\title{
Effect of Interrupted Ageing and Retrogression-Reageing Treatments on Fatigue Crack Growth with a Single Applied Overload in 7050 Aluminum Alloy
}

\author{
André Luís Moreira de Carvalho ${ }^{a} \mathbb{B}^{-}$, Juliana de Paula Martins ${ }^{b}$ \\ ${ }^{a}$ Departamento de Engenharia de Materiais, Universidade Estadual de Ponta Grossa, 84030-900, \\ Ponta Grossa, PR, Brasil \\ ${ }^{b}$ Departamento de Engenharia Química, Universidade Tecnológica Federal do Paraná, 84016-210, \\ Ponta Grossa, PR, Brasil
}

Received: May 26, 2017; Revised: February 13, 2018; Accepted: March 01, 2018

\begin{abstract}
The influences of interrupted ageing and retrogression and re-ageing heat treatments on fatigue crack growth with a single applied overload in 7050 aluminum alloy were investigated. The main aims were: to evaluate the influence of these heat treatment conditions on tensile properties, mainly fatigue crack growth rate and fracture process in the low-moderate $\Delta K$ region; to determine how both ageing treatments generate bimodal microstructure features as a contribution of the two conditions on the crack closure phenomenon; and the influence of the single applied overload to fatigue crack growth retardation. The results show that by using the RRA heat treatment condition it is possible to enhance the ductility without detrimental effects on the yield stress. T6I4-65 and RRA conditions contributed to enhancement of the crack closure phenomenon in the low-moderate $\Delta \mathrm{K}$ region, and, accordingly, produced a lower fatigue crack growth rate in relation to the traditional T7451 condition.
\end{abstract}

Keywords: T614-65, RRA condition, Fatigue crack growth, Fracture surface, Single overload, crack closure phenomenon, 7050 aluminum alloy.

\section{Introduction}

Al-Zn-Mg-Cu alloys are used widely for structural applications in the aircraft and aerospace industry due to their excellent mechanical properties, which are greatly influenced by fine precipitates and its precursors. Moreover, reductions in weight have always been a major criterion for the selection of materials for aerospace applications ${ }^{1}$. Aircraft structures operate under spectrum load fatigue through cyclic loading with variable stress amplitudes whereby load history effects occur, as can take place in structures subjected to high cycle fatigue loading conditions. Consequently, fatigue and fracture due to cyclic loading is the most common form of failure for the load-bearing structure components. Furthermore, changes in the cyclic mechanical-loading patterns could result in significant acceleration and/or retardation in the crack-growth rates.

Thus, the occurrence of positive overloads or high-low load sequences, for example, has a strong effect on the fatigue crack propagation behavior, and can retard crack growth ${ }^{2}$. Accordingly, numerous studies have demonstrated that a significant portion of the total fatigue life is consumed by fatigue damage evolution, which includes formation of a crack in a constituent particle, extension of a crack into the alloy matrix. In this period, the crack growth is discreetly slow, thus, for a large period of the crack growth the crack is still small ${ }^{3}$, as can be seen in Figure 1. Moreover, fatigue failure in critical locations of aircraft structures, such as upper fuselage parts, is the main cause of service life reduction in aircraft. An increase in the fatigue life of components can reduce the overall cost of a machine or an aircraft, and enhance damage tolerance of the structure ${ }^{4}$.

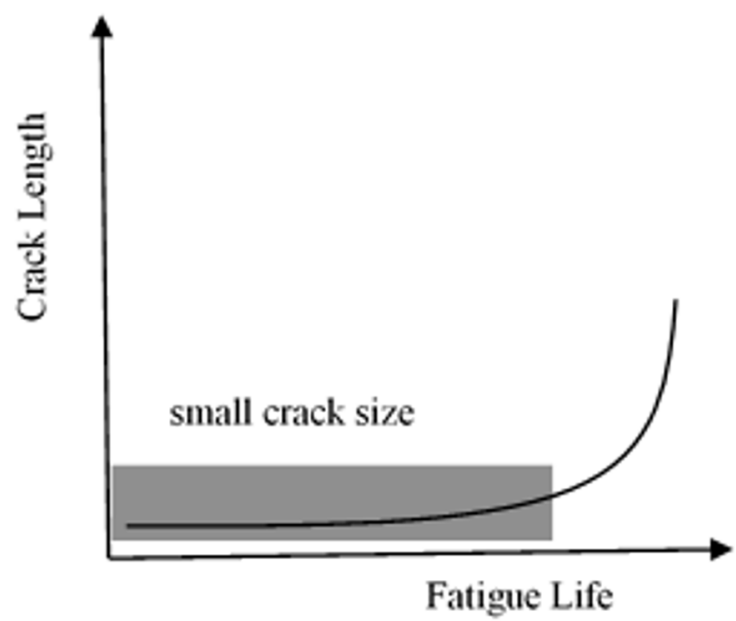

Figure 1. Schematic crack length versus fatigue life curve of a hypothetic material

Currently, Al-Zn-Mg-Cu alloys are used where strength is the main limiting design parameter. The choice of this alloy is attributed to a combination of high strength, fracture toughness, fatigue initiation and propagation resistance, together with stress corrosion cracking resistance that is required for such applications. Moreover, 7050-T7451 aluminum alloy plates are extensively used for manufacturing aircraft structural 
components due to their high strength, low density, excellent hot workability, fracture toughness and fatigue resistance $^{5}$. As a result, the overageing heat treatment T7451 is intensively used to reduce susceptibility to stress corrosion cracking. However, this heat treatment leads to a reduction of the maximum strength of this alloy ${ }^{6}$.

Retrogression and re-ageing (RRA) treatment is a three-step heat treatment proposed to replace the traditional overageing heat treatment of this alloy in order to improve the compromise between mechanical strength and corrosion resistance ${ }^{7,8}$. Furthermore, a new heat treatment termed T6I4-65 (I = interrupted) has been applied to 7050 aluminum alloys, in order to avoid the inverse correlations between some of the important tensile properties, such as yield strength and ductility ${ }^{9}$.

Accordingly, multiple-stage ageing treatments are developed for aluminum alloys to further enhance the mechanical property responses. These properties are directly related to the interaction between the precipitates and mobile dislocations of the bimodal microstructures containing both shearable and shear-resistant precipitates, generated by interrupted aging treatments. Microstructural effects have a strong influence on fatigue crack growth rates, and the presence of competing mechanisms during the fatigue crack propagation process ${ }^{10}$. However, few studies refer to T6I4-65 and RRA-treated 7050 aluminum alloys in order to explore the potential of multistage ageing treatments on the balance between yield stress and ductility, and the influence on fatigue crack growth behavior.

Therefore, the aim of the present work is to investigate the influence of two types of ageing heat treatments on the tensile properties and fatigue crack growth rate of 7050 aluminum alloy: the two-step T6I4-65 condition, and the three-step RRA condition (See experimental procedure). How both ageing heat treatments produce bimodal microstructure (precipitate structure exhibits a bimodal size distribution, that is the relation between length and thickness of precipitates), containing shearable and shear-resistant precipitates, these same produce the competing mechanisms themselves during the fatigue crack growth. Thus, the aims are to determine: which of these two conditions offer a better balance of strength and ductility; what contribution T6I4-65 and RRA conditions have on the crack closure phenomenon; and the consequences of the single applied overload effect on the retardation of fatigue crack growth. All these features were compared with the traditional T7451 condition, which is currently in use.

\section{Experimental Procedure}

\subsection{Material}

The material used in the present study was a 7050-T7451 aluminum alloy plate of 3" (76.8 $\mathrm{mm})$ thickness and the composition (in $\mathrm{wt} \%$ ) of $5.58 \mathrm{Zn}, 1.88 \mathrm{Mg}, 2.00 \mathrm{Cu}, 0.07 \mathrm{Fe}$, $0.02 \mathrm{Si}, 0.15 \mathrm{Zr}$, and $\mathrm{Al}$ balance, provided by the Embraer
Company. From the aluminum alloy plate, it was machined strip of $160 \times 60 \times 15 \mathrm{~mm}$ dimensions from the longitudinal (LD) to rolling direction. Accordingly, these same dimensions were used to perform heat treatments and posterior machining of specimens for tensile and fatigue crack growth tests.

\subsection{Heat treatment}

Table 1 shows the two types of heat treatment considered in the present study, carried out according to the following schedules. The T6I4-65 condition involved solution treatment at $758 \mathrm{~K}\left(485^{\circ} \mathrm{C}\right)$ for $4 \mathrm{~h}$, followed by water quenching. Then ageing was interrupted at $403 \mathrm{~K}$ $\left(130^{\circ} \mathrm{C}\right)$ for $15 \mathrm{~min}$, followed by ageing at $338 \mathrm{~K}\left(65^{\circ} \mathrm{C}\right)$ for two months. The second condition, denoted as the RRA condition, was solution treated at $758 \mathrm{~K}\left(485^{\circ} \mathrm{C}\right)$ for $4 \mathrm{~h}$, water quenched, and aged at $403 \mathrm{~K}\left(130^{\circ} \mathrm{C}\right)$ for $24 \mathrm{~h}$ followed by retrogression at $458 \mathrm{~K}\left(185^{\circ} \mathrm{C}\right)$ for 20 min, and finally ageing at $338 \mathrm{~K}\left(65^{\circ} \mathrm{C}\right)$ for two months. Both heat ageing treatments are illustrated in Figure 2 (a and $b$, respectively). The other condition considered for reference was the as-received T7451 condition.

Table 1. Ageing heat treatment schedule for the T7451, T6I4-65 and RRA conditions

\begin{tabular}{|c|c|c|c|c|}
\hline Condition & $\begin{array}{c}\text { Solution } \\
\text { heat } \\
\text { treatment }\end{array}$ & Ageing & $\begin{array}{l}\text { Reversion } \\
\text { treatment }\end{array}$ & $\begin{array}{c}\text { Re-ageing } \\
\text { treatment }\end{array}$ \\
\hline T7451 & & As received & & \\
\hline RRA & $\begin{array}{c}758 \mathrm{~K} \\
\left(485^{\circ} \mathrm{C}\right)\end{array}$ & $\begin{array}{c}\text { Ageing } \\
\text { at } 403 \mathrm{~K} \\
\left(130^{\circ} \mathrm{C}\right) \text { for } \\
24 \mathrm{~h}\end{array}$ & $\begin{array}{l}\text { Reversion } \\
\text { at } 458 \mathrm{~K} \\
\left(185^{\circ} \mathrm{C}\right) \\
\text { for } 20 \mathrm{~min}\end{array}$ & $\begin{array}{c}\text { Re-ageing } \\
\text { at } 338 \mathrm{~K} \\
\left(65^{\circ} \mathrm{C}\right) \\
\text { for two } \\
\text { months }\end{array}$ \\
\hline T6I4-65 & for $4 h$ & $\begin{array}{c}\text { Ageing } \\
\text { interrupted } \\
\text { at } 403 \mathrm{~K} \\
\left(130^{\circ} \mathrm{C}\right) \text { for } \\
15 \mathrm{~min}\end{array}$ & & $\begin{array}{c}\text { Ageing } \\
\text { at } 338 \mathrm{~K} \\
\left(65^{\circ} \mathrm{C}\right) \\
\text { for two } \\
\text { months }\end{array}$ \\
\hline
\end{tabular}

\subsection{Fatigue crack growth test}

Fatigue crack propagation testing was performed under constant stress amplitude using a servohydraulic $15 \mathrm{kN}$ fatigue machine on compact tension specimens, with plate width (W) of $50 \mathrm{~mm}$ and thickness of $9.5 \mathrm{~mm}$, machined from the plate with L-T orientation, with the crack growth aligned with the transverse direction, as can be seen in Figure 3. All samples were pre-cracked as described in ASTM E 647-05 ${ }^{11}$. Crack length was measured from a digital camera attached to a Questar long-range telescope. Thus, the fatigue test took place with a maximum load $\left(\mathrm{P}_{\max }\right)$ of $4 \mathrm{kN}$ using a frequency of $10 \mathrm{~Hz}$, and a stress ratio, $\mathrm{R}$, of 0.1 . Moreover, single overload (OL) of $8 \mathrm{kN}$ (denote an overload ratio, OLR= $\mathrm{OL} / \mathrm{P}_{\max }$ of 2) was applied when the size crack reached approximately $5.7 \mathrm{~mm}$, for all conditions investigated. 
a)

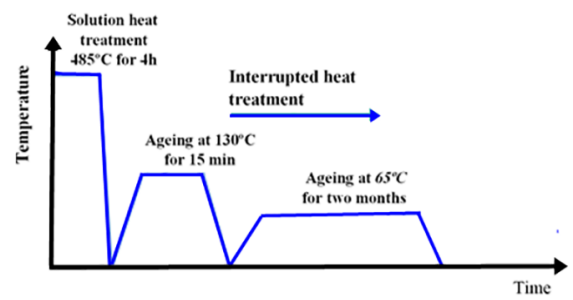

b)

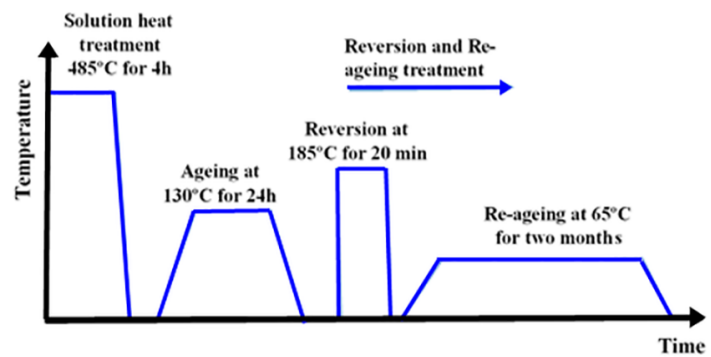

Figure 2. Schematic diagram of ageing heat treatment procedure from the a) T6I4-65 and b) RRA conditions

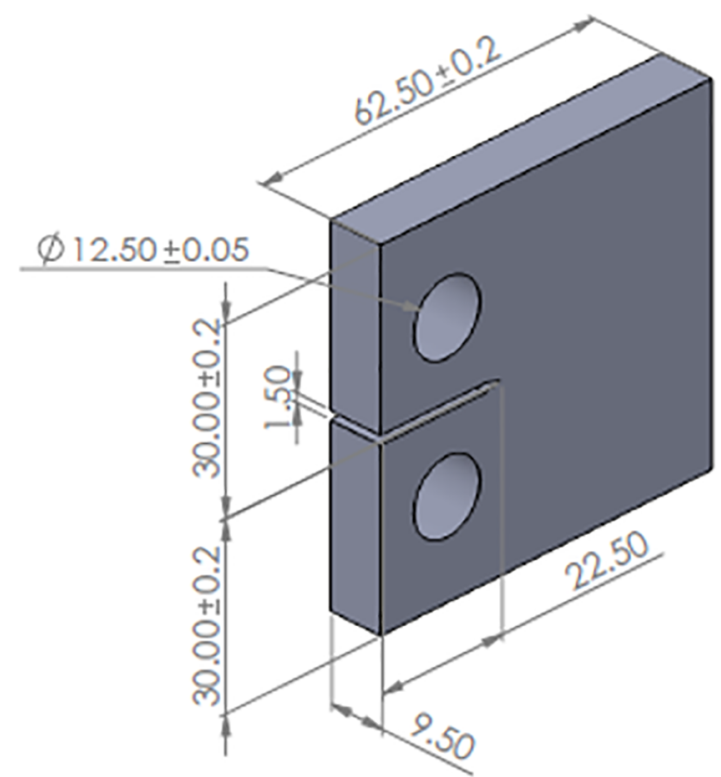

Figure 3. Geometry of the compact tension aluminum alloy specimen (dimensions in $\mathrm{mm}$ )

\subsection{Crack opening displacement (COD)}

The digital image correlation (DIC) method described by $^{12}$ was applied in this work. Thus, during the fatigue crack growth testing, several videos of the displacement of the crack face along of different crack lengths were recorded. Namely, videos were recorded during three load cycles at a test frequency of $0.25 \mathrm{~Hz}$. The resolution used during each recording process was $1280 \times 1024$ pixels, (with 1 pixel corresponding to $1.025 \mu \mathrm{m}$ ) with 25 frames per second; consequently, 300 frames were achieved. Once the images were acquired, crack opening displacement (COD) was calculated using digital image correlation from Istress software. The COD measurements were taken from a location behind the crack tip, corresponding to $150 \mu \mathrm{m}$ from the crack tip, as can be noticed in Figure 4. Moreover, a single overload (OL) of $100 \%$ was applied to evaluate its influence on the retardation of fatigue crack growth rate, and the subsequent crack propagation process for the T7451, T6I4-65 and RRA conditions investigated.

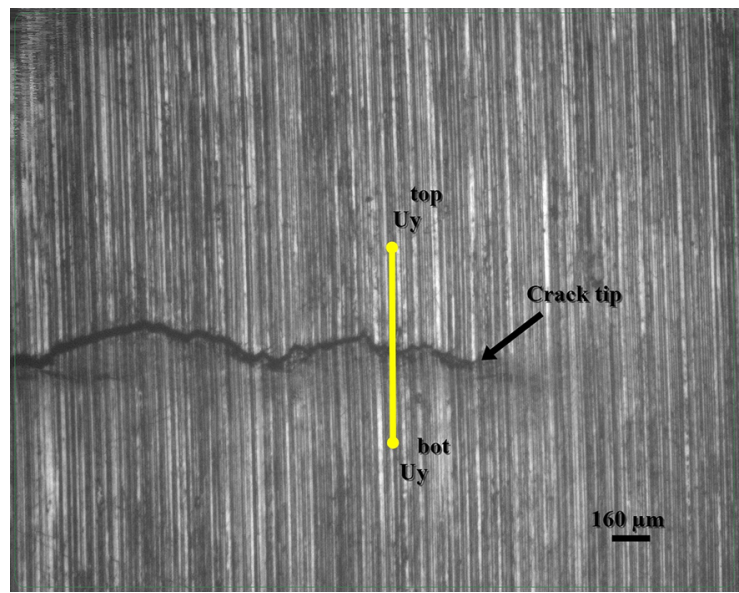

Figure 4. COD taken at distance of $150 \mu \mathrm{m}$ from the behind the crack tip by subtracting the vertical displacements of the top flank $\left(U_{y}^{\text {top }}\right)$ and bottom flank $\left(U_{y}^{\text {bot }}\right)$ of the crack tip

\subsection{Fatigue fracture surface analysis}

Fractography analysis of fatigue crack surfaces was carried out at the locations of crack growth in the near-threshold, low and high $\Delta \mathrm{K}$ regions, as well as in the rupture region, for the T7451, T6I4-65, and RRA conditions. All fracture analyses were performed using a Tescan focused ion beam scanning electron microscope (FIB/SEM) LIRA 3XM using secondary electron mode.

\section{Results and Discussion}

\subsection{Ageing heat treatment effects on the mechanical properties}

\subsubsection{Tensile properties}

Table 2 shows the tensile properties of the test aluminum alloy after the T7451, T6I4-65 and RRA treatment conditions. From these results it is possible to observe that for the traditional 
T7451 condition, the ultimate tensile strength (UTS) and yield strength (YS) were $592 \mathrm{MPa}$ and $492 \mathrm{MPa}$, respectively. Compared with these results of T7451 condition, the UTS and YS of the T6I4-65 condition was lower by $10.86 \%$ and $8.85 \%$, respectively, whereas the UTS and YS of the RRA condition was higher by $3.58 \%$ and $9.76 \%$, respectively. In a comparison between the T6I4-65 and RRA conditions, the UTS and YS of the RRA condition were higher by $14.83 \%$ and $19.46 \%$, respectively. Moreover, a significant difference among the three conditions is attributed to reduction in area (RA). For both T6I4-65 and RRA conditions the RA values of $38.2 \%$ and $22.8 \%$ were higher than the $3.7 \%$ for the $\mathrm{T} 7451$ condition. This indicates that both new conditions have better fracture toughness as a consequence of higher ductility. On the other hand, Lumley et al. ${ }^{13}$ used a new heat treatment (T6I4-65) in the Al-Zn-Mg-Cu AA7050 alloy and their results showed an increase in fracture toughness without significant changes in the elongation, but with a decrease in the YS. Therefore, these experiments show that it is possible to substantially increase the ductility of the AA7050 alloy without significant detrimental effects on the UTS and YS by using both T6I4-65 and RRA conditions, compared to the traditional T7451 condition.

Table 2. The tensile properties of the investigated T7451, T6I465 and RRA conditions.

\begin{tabular}{lccc}
\hline $\begin{array}{l}\text { AA7050 } \\
\text { Condition }\end{array}$ & YS (MPa) & UTS (MPa) & R.A. (\%) \\
\hline T7451 & $492 \pm 10.5$ & $592 \pm 23$ & $3.7 \pm 1.2$ \\
T6I4-65 & $452 \pm 10.3$ & $534 \pm 14.5$ & $38.2 \pm 2.9$ \\
RRA & $540 \pm 15.5$ & $613.20 \pm 4.8$ & $22.8 \pm 3.2$ \\
\hline
\end{tabular}

\subsubsection{Fatigue crack growth rate}

Figure 5 shows the comparison of fatigue crack growth rate curves of the AA7050 alloy after the T7451, T6I4-65 and RRA treatment conditions as function of the applied stress intensity ranges. A significant difference throughout the fatigue crack rate for both the T6I4-65 and RRA conditions can be seen in relation to $\mathrm{T} 7451$ condition under low-moderate stress intensity. The difference in the fatigue crack growth rate among the three conditions becomes clearer when $\mathrm{da} /$ $\mathrm{dN}$ is plotted against the ratio $(\Delta \mathrm{K}(\sqrt{\mathrm{E} \sigma y s}) \sqrt{\mathrm{m}})$, as shown in Figure 6. Clearly, it is possible to notice that when the crack size is small or the $\Delta \mathrm{K}$ is low the T6I4-65 and RRA conditions exhibit the slowest crack growth rates. Furthermore, both the T6I4-65 and RRA conditions exhibit similar "thresholds".
However, with increasing $\Delta \mathrm{K}$, the differences in the crack growth rate for the three conditions narrow and the T7451 condition exhibits lower crack growth rates than the other two conditions. To demonstrate these difference of fatigue crack growth behavior, the Paris constants, and the $\mathrm{da} / \mathrm{dN}$ values at specified $\Delta \mathrm{K}$ regions between 8 and $22 \mathrm{MPa} V_{\mathrm{m}}$ were determined to compare the three conditions investigated, and these are shown in Table 3. The ' $\mathrm{C}$ ' and ' $\mathrm{n}$ ' values for the T7451 condition are found to be, $1.688 \times 10^{-10}$ and 2.96 , respectively. For the T6I4- 65 condition these values are 0.028 $\times 10^{-10}$ and 4.46 , respectively, and for RRA they are $0.003 \times$ $10^{-10}$ and 5.14, respectively. It is evident that the value of ' $n$ ' increases from 2.96 to 5.14 as a result of the ageing condition.

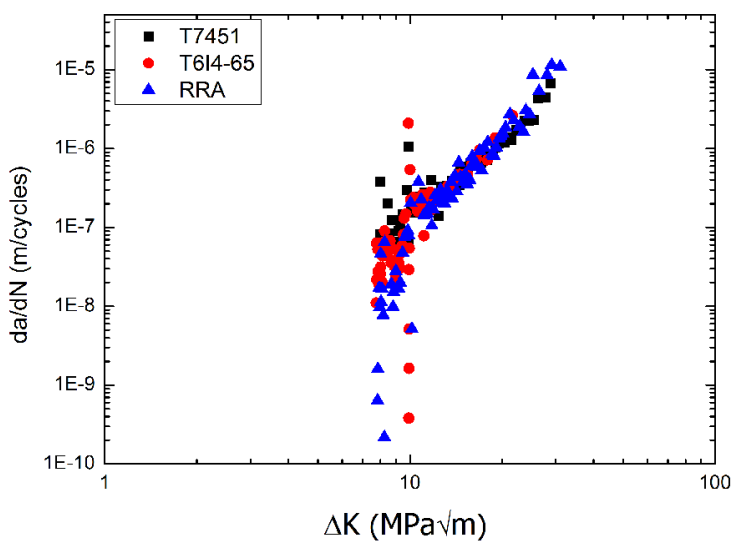

Figure 5. Fatigue crack growth rate versus $\Delta \mathrm{K}$ curves for the three conditions

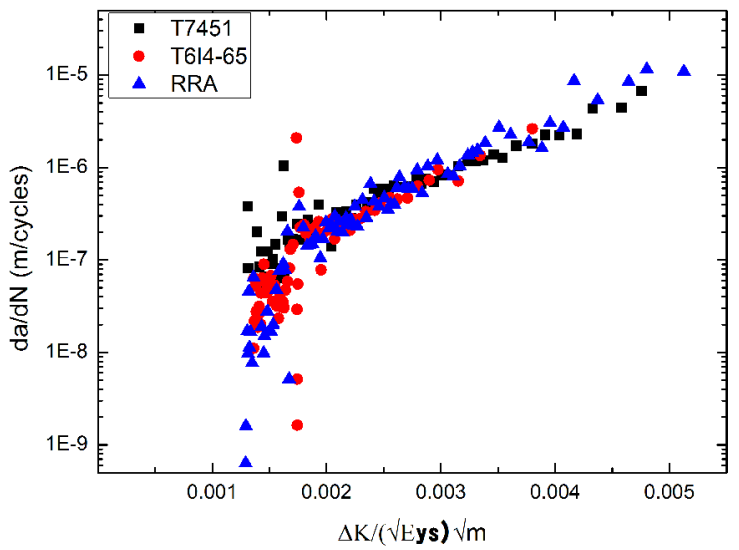

Figure 6. Fatigue crack growth rate versus $\Delta K(\sqrt{ }$ E $\sigma y s) \sqrt{ }$ m curves for AA7050 alloys after the three ageing treatments

Table 3. Paris constants and the $\mathrm{da} / \mathrm{dN}$ values corresponding to various $\Delta \mathrm{K}$ regions for the three conditions.

\begin{tabular}{lccccccc}
\hline $\begin{array}{l}\text { Aging } \\
\text { treatment } \\
\text { condition }\end{array}$ & $\mathrm{C}$ & $\mathrm{n}$ & \multicolumn{5}{c}{$\mathrm{da} / \mathrm{dN}=\mathrm{C}(\Delta \mathrm{K})^{\mathrm{n}}(\mathrm{m} / \mathrm{cycle})$} \\
\hline T7451 & $1.688 \times 10^{-10}$ & 2.96 & $0.80 \times 10^{-7}$ & $1.54 \times 10^{-7}$ & $5.11 \times 10^{-7}$ & $11.98 \times 10^{-7}$ & $15.88 \times 10^{-7}$ \\
T6I4-65 & $0.028 \times 10^{-10}$ & 4.46 & $0.30 \times 10^{-7}$ & $0.81 \times 10^{-7}$ & $4.93 \times 10^{-7}$ & $17.77 \times 10^{-7}$ & $27.19 \times 10^{-7}$ \\
RRA & $0.003 \times 10^{-10}$ & 5.14 & $0.13 \times 10^{-7}$ & $0.41 \times 10^{-7}$ & $3.33 \times 10^{-7}$ & $14.60 \times 10^{-7}$ & $23.83 \times 10^{-7}$ \\
\hline
\end{tabular}


Moreover, it can be seen that between at the $\Delta \mathrm{K}$ regions of 8 and $15 \mathrm{MPa} \sqrt{\mathrm{m}}$ the RRA condition has a lower crack growth rate than the T7451 condition, while the T6I4-65 condition has revealed intermediary behavior.

\subsection{Ageing heat treatment influence on the fracture feature}

Figure 7(a-c) displays the effect of the ageing heat treatments (T7451, T6I4-65 and RRA, respectively) on the fracture features (by SEM fractographs) of the fatigue crack growth specimens tested at the near-threshold region. It is possible to notice that crack growth occurs on multiple facets at different angles with respect to each other for all three conditions investigated. This formation of facets is more evident for the RRA condition, in which the features are also larger than for the T6I4-65 and T7451 conditions. In Figure 7(c), changes in the orientation of facets can be noted (indicated by black arrows), which are likely associated with the crack path crossing a twist grain boundary.

Figure 8(a-c) shows the results of the investigation of the fracture surfaces that took place in the low $\Delta \mathrm{K}$ region. For the T7451 condition (Fig. 8(a)), it is possible to notice the formation of deep pockets and the absence of facets. Alternatively, for the T6I4-65 (Fig. 8(b)) and RRA (Fig. 8(c)) conditions, shallow pockets, a predominance of small flat facets (black arrows in Fig. 8(b)), and small and large facets (Fig. 8(c)) containing multiple wavy regions (encircled using dashed lines) highlight the influence of the underlying grain structure. However, the varied surface features suggest the presence of competing mechanisms of crack propagation for both T6I4-65 and RRA conditions.

According to Gupta ${ }^{14}$, the difference in accumulated plastic strain between the matrix and the slip bands during cyclic loading is responsible for the difference in facet size. This explains the absence of facets for the T7451 condition, as a consequence low ductility.

Likewise, void formation at the coarse grain boundary is also observed, except for the RRA condition, as can be seen in Figure 9(a-c). In this specific case, for the T7451 condition it is possible to notice larger void formations at the grain boundary, as seen in Figure 9(a) with higher magnification. Moreover, for all three conditions it is possible to notice the presence of secondary cracks (black arrows).
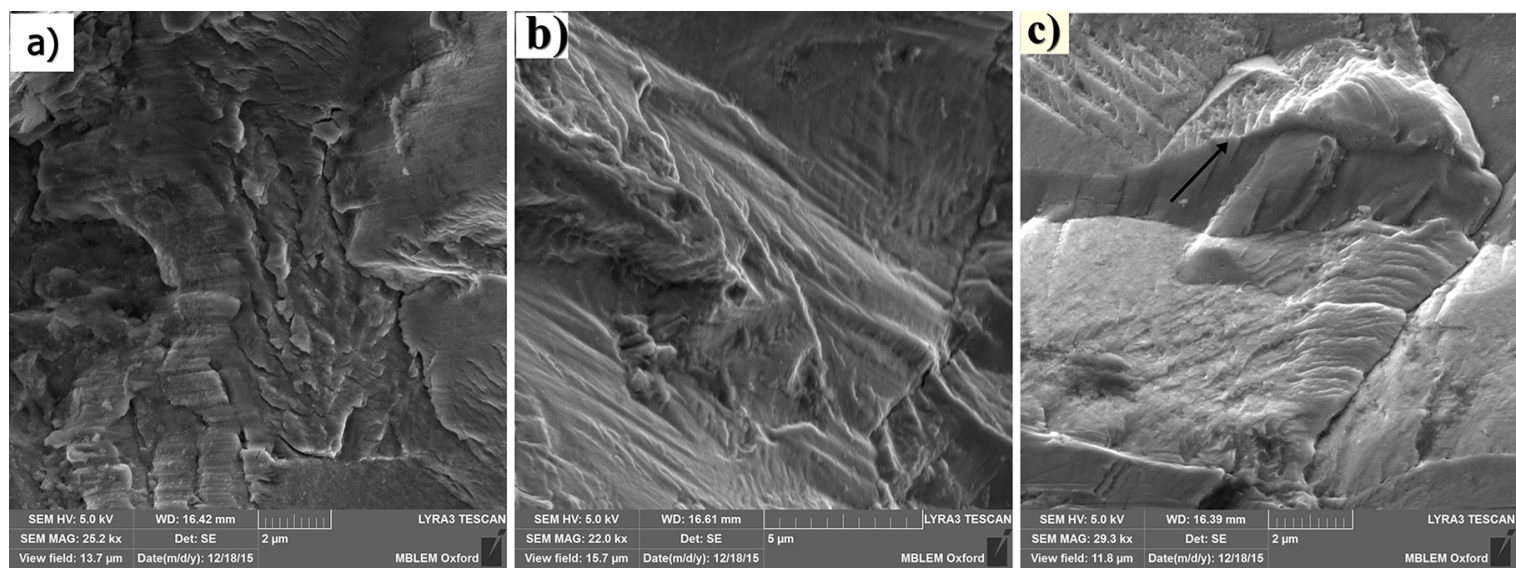

Figure 7. Fracture surface analysis by SEM at the near-threshold region of the AA7050 alloy in the three conditions (a) T7451 and (b) T6I4-65 and (c) RRA (crack propagation direction is from left to right)
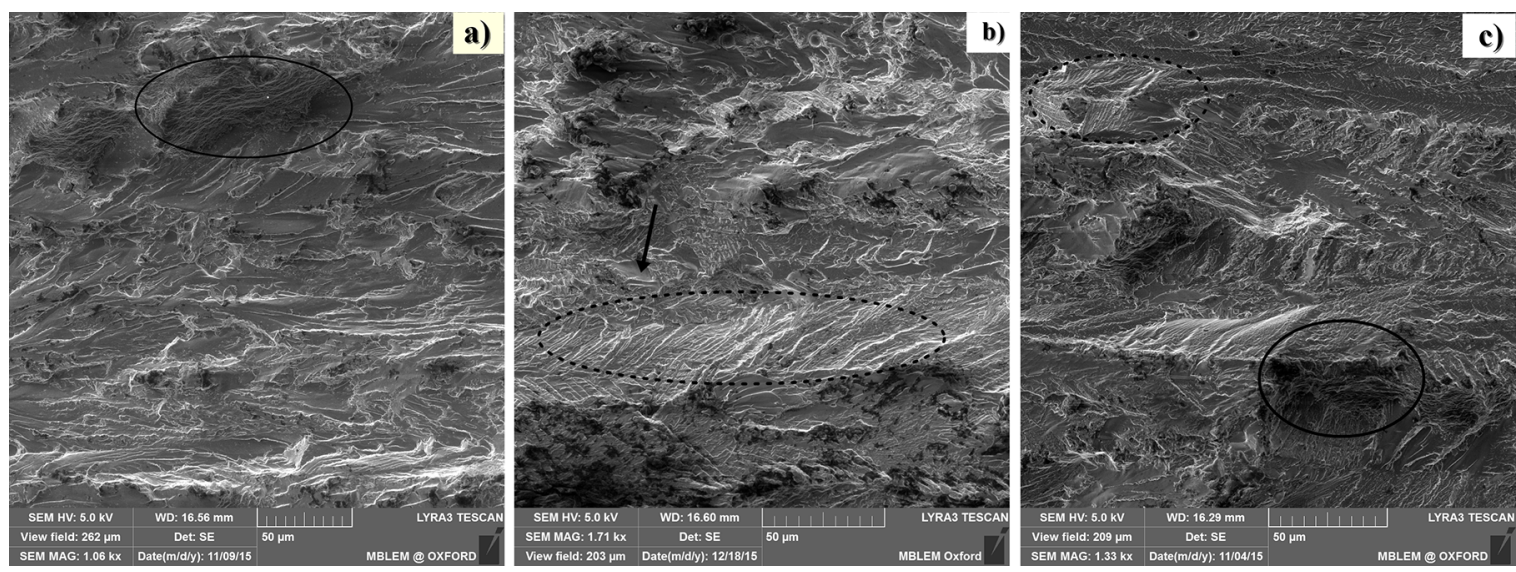

Figure 8. Fracture surface SEM images in the Paris growth regime (low $\Delta \mathrm{K}$ region) of the AA7050 alloy for the three conditions (a) T7451, (b) T6I4-65, and (c) RRA. Arrows highlight flat facets (crack propagation direction is from left to right) 

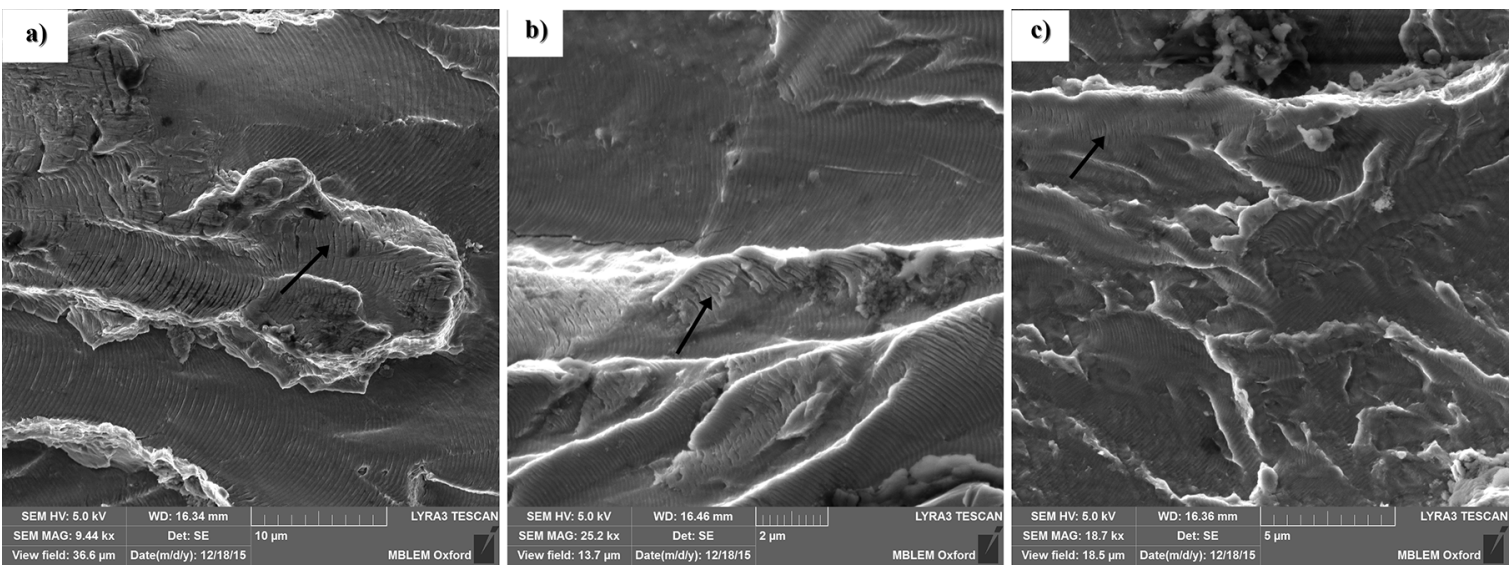

Figure 9. SEM fractographs in the Paris growth regime (low $\Delta K$ region) of the AA7050 alloy for the three conditions: (a) T7451 showing large void formation at the coarse grain boundary, (b) T6I4-65 showing small void formation at the coarse grain boundary, and (c) RRA showing a lack of void formation. Arrows highlight secondary cracks (crack propagation direction is from left to right)
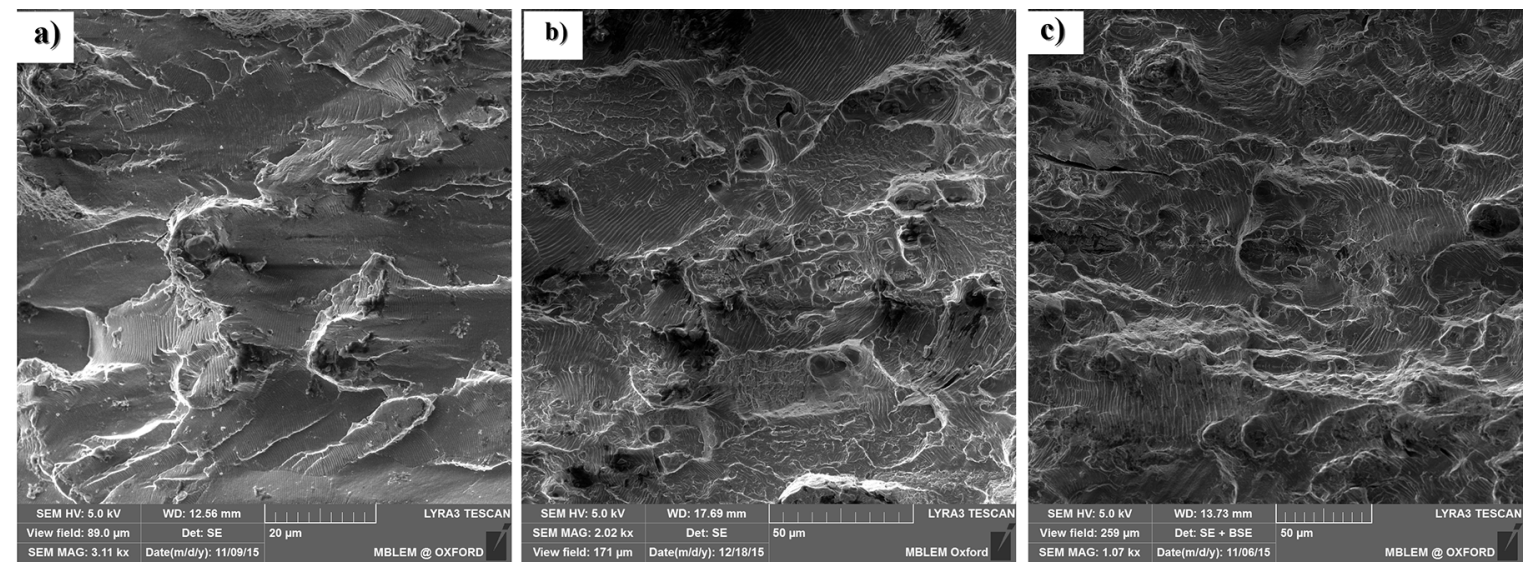

Figure 10. Fracture surface SEM images in the Paris growth regime (high $\Delta \mathrm{K}$ region) of the AA7050 alloy for the three conditions showing: (a) the absence of facets for the T7451, and the difference between striation arrangement orientation for both (b) T6I4-65 and (c) RRA (crack propagation direction is from left to right)

Figure 10 (a-c) shows SEM fracture surface images of the crack growth in the high $\Delta \mathrm{K}$ region for the three conditions. The absence of facets, observed in the low $\Delta \mathrm{K}$ region, are also seen for the $\mathrm{T} 7451$ condition, but to a greater degree due to the high $\Delta \mathrm{K}$. Similar features for both T6I4-65 and RRA conditions were also observed in this region. However, it is possible to observe in Figure 10(b, c) that the orientation of striation alignment differs from patch to patch.

This suggests that the crack front and the crack growth direction changes during propagation, in that the crack front is probably not maintained as a straight line, but is likely to be tortuous, as a consequence competing mechanisms. Furthermore, void formation observed for the RRA condition can be associated with the crack crossing grain boundaries.

Figure 11 (a-c) displays fractographic features from the fatigue rupture region for the T7451, T6I4-65, and RRA conditions. A predominance of ductile fracture surfaces characterized by the large dimples of the order of 2.5-9.5 $\mu \mathrm{m}, 2.2-17.4 \mu \mathrm{m}$ and 2.0-12.0 $\mu \mathrm{m}$ in diameter, can be seen for all three conditions, respectively.
This feature is a consequence the differences in ductility. Furthermore, it is possible to notice aggregates of secondary particles within these dimples, and intergranular failure along the grain boundaries in the fracture surface (Fig. 11(b)); however, the failure mode is predominantly transgranular for the three conditions investigated.

On the other hand, for all regions investigated for the three conditions, at the fractured surface a chaotic morphology was always observed, as can be seen in Figure 8(a) and (c) (region encircled using a solid line). Shijve ${ }^{15}$ found this same feature in the 7075-T6 aluminum alloys and showed that the chaotic morphology occurs parallel to the material surface. Moreover, results reported ${ }^{16}$ on the fatigue crack growth in 2524-T3 samples also observed a chaotic nature related to the grain boundaries.

Table 4 displays the measured striation spacing at the fractured surface for the three conditions. It is known that the spacing between adjacent striations correlates with the average crack growth rate per cycle for cyclic loads ${ }^{6}$. 

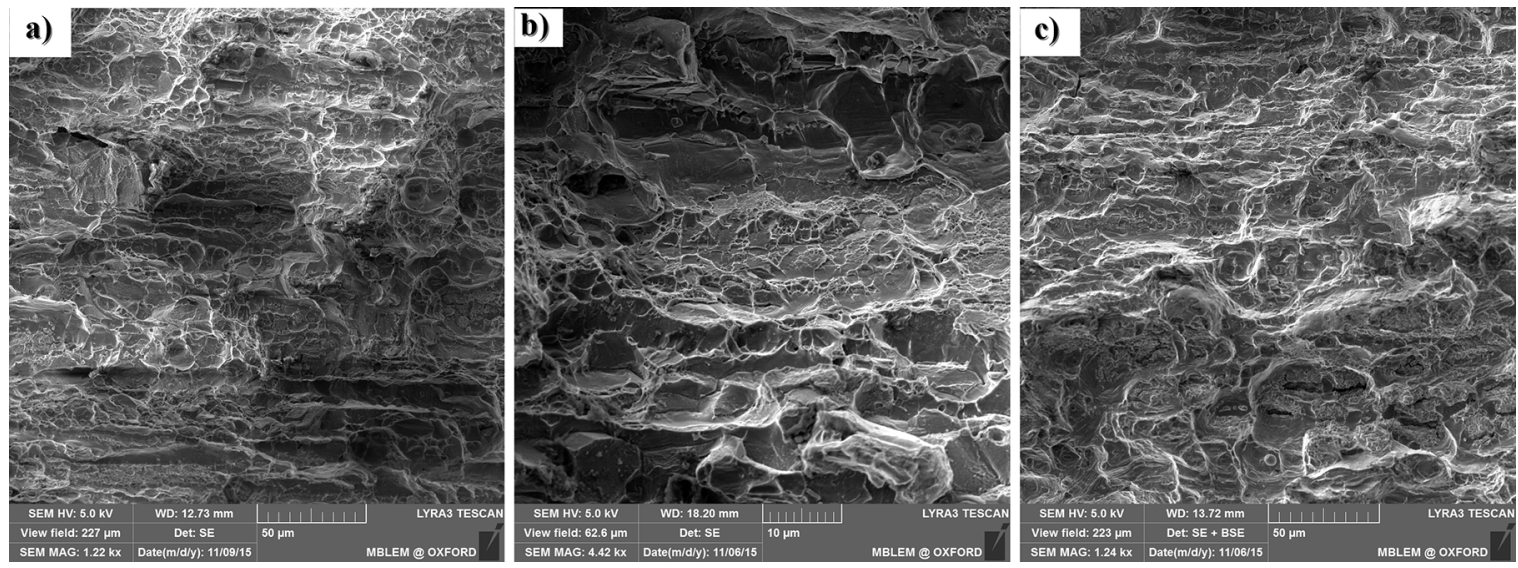

Figure 11. Fracture surface SEM images from the rupture region of the AA7050 alloy for the three conditions showing the predominance of the ductile fracture surface (a) T7451, (b) T6I4-65, and (c) RRA (crack propagation direction is from left to right)
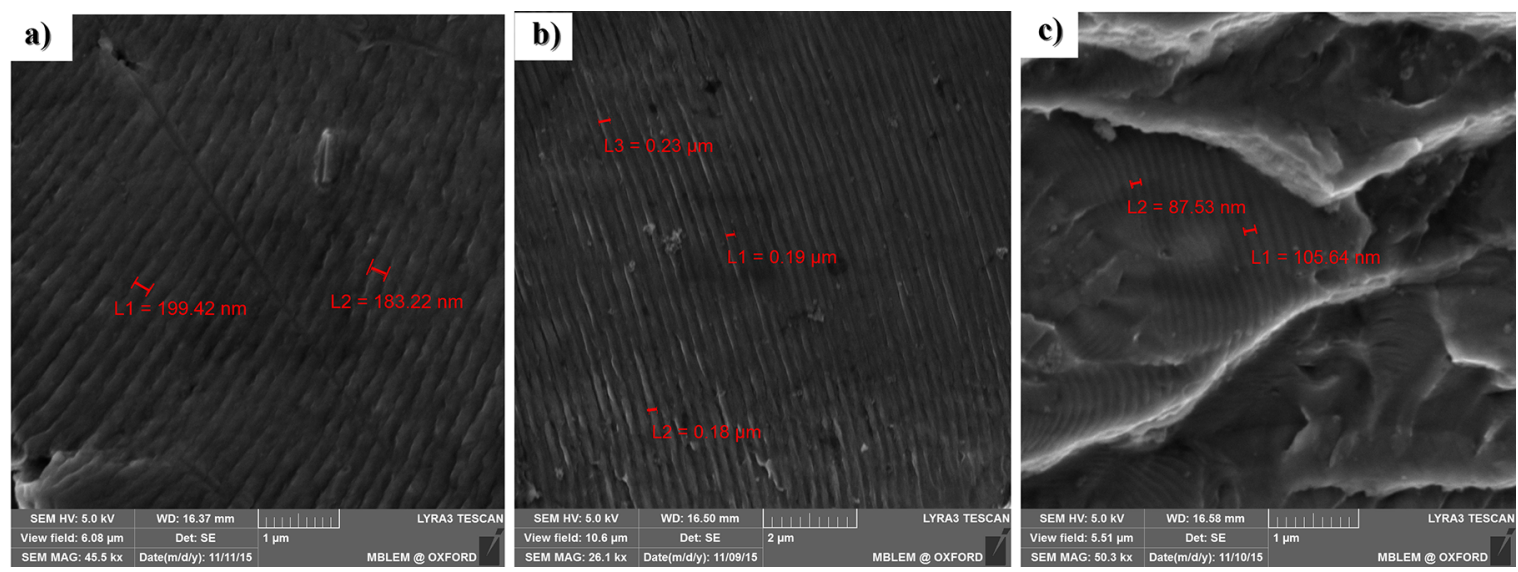

Figure 12. SEM fractographs in the low $\Delta \mathrm{K}$ region, showing the measured striation spacing from the three conditions investigated (a) T7451, (b) T6I4-65, and (c) RRA (crack propagation direction is from left to right)

Table 4. Experimental results of the measured striation spacing from fractured surface at the low and high $\Delta \mathrm{K}$ region of the T7451, T6I465 , and RRA conditions.

\begin{tabular}{lcc}
\hline Condition & $\begin{array}{c}\text { Average striation }(\mu \mathrm{m}) \\
\text { Low } \Delta \mathrm{K}\end{array}$ & High $\Delta \mathrm{K}$ \\
\hline T7451 & 0.191 & 0.595 \\
T6I4-65 & 0.121 & 0.490 \\
RRA & 0.097 & 0.485 \\
\hline
\end{tabular}

Accordingly, this suggests a correlation with the fatigue crack growth rate, as shown in Table 2.

Thus, from Table 4 it can be seen that both T6I465 and RRA conditions in the low $\Delta \mathrm{K}$ region have a narrower fatigue striation distance than the traditional T7451 condition; this can also be seen in Figure 12 (a-c). This indicates a slow fatigue crack growth rate, and hence the higher resistance to fatigue crack growth of these two conditions in relation to the T7451 condition.

\subsection{Influence of ageing treatment on the crack closure phenomenon}

Understanding fatigue-damage mechanisms is crucial for the improvement of damage-tolerance design as well as development of new ageing heat treatments to obtain excellent fatigue crack growth resistance. The concept of fracture surface interaction leading to a decrease of stress intensity at the crack tip and to an increase of fatigue life was first stated in $1963{ }^{17}$. Crack closure is one of the important mechanisms that can explain many load-interaction effects on the fatigue-crack-growth behavior under constant and variable amplitude loading. Since Elber discovered plasticityinduced crack closure, many researchers observed various forms of fatigue crack closure that are induced by a variety of mechanical, microstructural, and environmental factors, such as: plasticity-induced crack closure, oxide-induced crack closure, roughness-induced crack closure, viscous fluid-induced crack closure, and transformation-induced crack closure. Thus, the understanding of crack closure 
is a subject of discussion within the fatigue community. This is caused mainly by difficulty in its measurement and the complexity of the crack closure mechanics ${ }^{18}$. Recent advances in optical experimental mechanics of fatigue crack growth and fracture problems, such as the digital image correlation (DIC), have made it possible to infer the local crack-tip displacement fields with sufficient accuracy ${ }^{19,20}$. Accordingly, DIC was also used to study crack closure and the effect of crack closure due to a single peak overloading during fatigue cycling of different thicknesses of contact tension samples ${ }^{21}$. Therefore, in the present work, a main aim is to investigate the effect of the three conditions on the crack closure phenomenon in the low-moderate $\Delta \mathrm{K}$ region, and also their influence with applied overload on the fatigue crack growth rate. In this way, calculation of the opening/ closing loads in the crack closure contribution on crack growth retardation was not taken into account, and only a near-tip COD as a function of the cycle fraction was obtained. Thus, COD values from the correlated images through a processing routine (Istress) are used to obtain the COD at a distance behind the crack tip by subtracting the vertical displacements of the top flank $\left(U_{y}^{\text {top }}\right)$ and bottom flank $\left(U_{y}^{\text {bot }}\right)$ of the crack tip (Fig. 4) according to Eq. 1:

$$
C O D=U_{y}^{\text {top }}-U_{y}^{\text {bot }}
$$

The COD versus cycle fraction is characterized at a distance of $150 \mu \mathrm{m}$ behind the crack-tip through selected loading cycles, as can be seen Figure 13. This specific case shows a typical variation of COD with the cycle fraction, at the moment when crack length was $\approx 5.7 \mathrm{~mm}$ for the T7451, T6I4-65 and RRA conditions. It can be clearly seen for three conditions investigated that the flat regions at the bottom of the COD values (i.e., close to 0 ) along cycle fraction correspond to crack closure phenomenon. It also shows that COD values decrease with an increase of the extension of the flat regions, indicating that the crack closure effect is more effective. For the RRA condition the COD value is $3.9 \mu \mathrm{m}$, while for the T6I4-65 condition it is $4.8 \mu \mathrm{m}$, and for the T7451 condition is $5.7 \mu \mathrm{m}$, indicating that the RRA condition induces a higher crack closure effect than both the T6I4-65 and T7451 conditions. This feature is confirmed in Figure 14, which shows the COD values in the function stress intensity factor range, $\Delta \mathrm{K}$, for the three conditions investigated. It can be seen that for the RRA condition in the low $\Delta \mathrm{K}$ region, between 8 to $10 \mathrm{MPa} \mathrm{m}^{0.5}$, the fatigue crack growth retardation is higher in relation to the T7451 and T64-65 conditions, as a consequence the lower $\mathrm{COD}$ value. However, after the $\Delta \mathrm{K}=10 \mathrm{MPa} \mathrm{m}^{0.5}$ region, both the T6I4-65 and RRA conditions show similar fatigue crack growth retardation behavior, while the T7451 condition has lower fatigue crack growth retardation due to the higher COD values. On the other hand, in the $\Delta \mathrm{K}>16 \mathrm{MPa} \mathrm{m}^{0.5}$ region the T7541 condition begins to experience fatigue crack growth retardation similar to the other two other conditions.

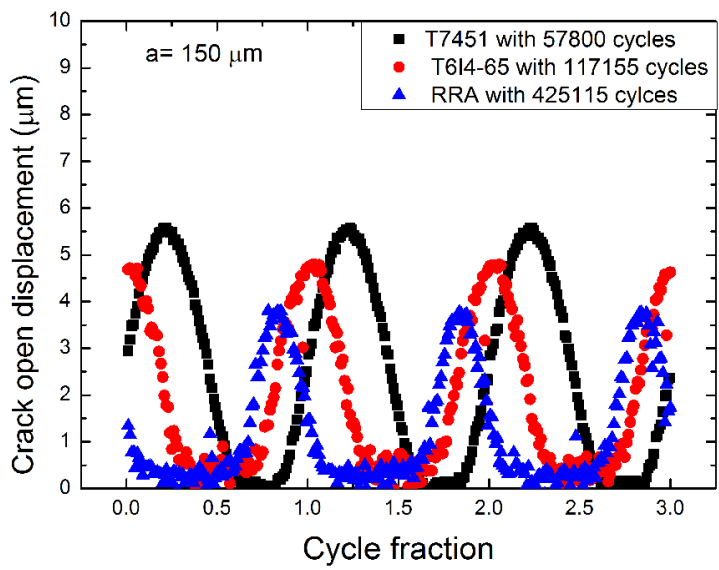

Figure 13. The COD at a crack length of $\mathrm{a}=150 \mu \mathrm{m}$ behind the crack tip for the T7451, T614-65, and RRA conditions with 57,800, 117,155 and 425,115 cycles, respectively

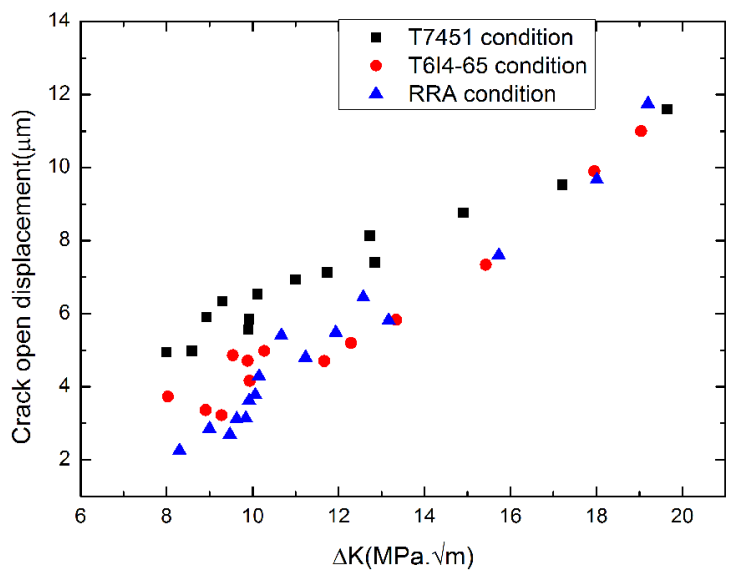

Figure 14. COD in the function stress intensity factor, $\Delta K$, from the T7451, T6I4-65, and RRA conditions

It is well known that the effective stress intensity factor range, $\Delta \mathrm{K}_{\text {eff }}$, was developed based on the crack closure concept as the effective driving force for crack growth. Accordingly, this indicates that the RRA condition promotes lower effective driving force for fatigue crack growth compared to the T7451 and T6I4-65 conditions in the small $\Delta \mathrm{K}$ region. This evidence is consistent with that shown in Table 3 and Figures 5 and 6.

\subsection{Influence of ageing treatment on the fatigue crack growth with applied overload}

It is also known that the application of an overload causes a decrease in the crack growth due to the retardation of fatigue crack growth ${ }^{2}$. Thus, there are two important aspects of the single applied overload: first, that the superposition of single tensile overload on the base loading results in crack growth retardation or a full crack arrest, ${ }^{22}$ which leads to an increase in service life; and second, the study of the single overload effect on the crack propagation rate of subsequent cycles forms a basis for the study of variable amplitude loading ${ }^{4}$. Consequently, several mechanisms 
are proposed to explain crack growth retardation following single peak tensile overloads, which include studies based on compressive residual stress ahead of the crack tip $^{23}$, crack tip blunting ${ }^{24}$, crack tip strain hardening ${ }^{25}$, crack branching, reversed yielding and fracture surface roughness, and the crack closure effect ${ }^{26}$. However, the precise micromechanisms responsible for these phenomena are not fully understood. The effects of a single tensile overload are the subject of much attention because this type of loading can lead to a significant increase in the fatigue lifetime as a consequence of retardation. In this sense, the retardation effect is generally measured in terms of delayed cycles, $\mathrm{Nd}$, before the original steady-state conditions are re-established. Thus, an aim of present work is to investigate the single applied overload effect from measured delayed cycles, $\mathrm{Nd}$, on the fatigue crack growth in the T7451, T6I4-65 and RRA conditions. Figure 15 shows the crack length versus the number of cycles for the three conditions tested under constant amplitude loading, in which a single peak overload (100\% overload) was applied at a crack length of nearly $5.7 \mathrm{~mm}$.

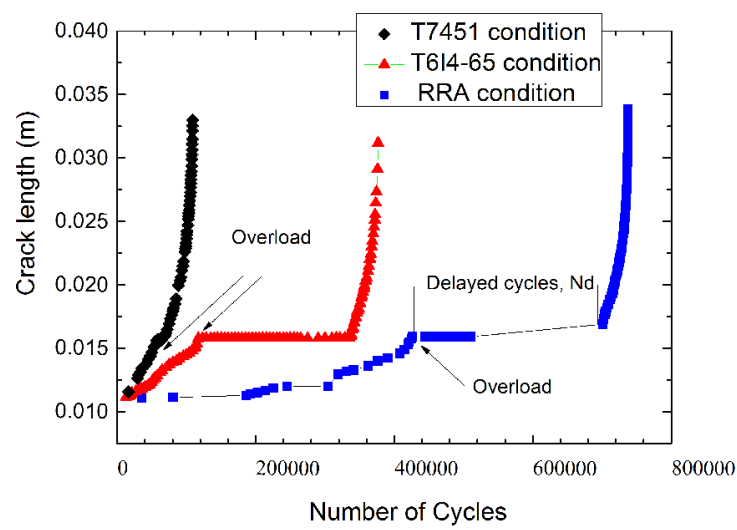

Figure 15. Crack length versus number of cycles with applied overload for the three conditions

A strong influence of applied overload is apparent on the T6I4-65 and RRA conditions when compared to the T7451 condition, in terms of the Nd values (Fig. 15). For both the RRA and T64-65 conditions the delayed cycles were $\mathrm{Nd}=$ 274,471 and $\mathrm{Nd}=218,080$, respectively, whereas for the $\mathrm{T} 7451$ condition $\mathrm{Nd}=6,148$. As a result, the applied overload on the RRA and T6I4-65 conditions resulted in an effective increase in the accumulation life for these two conditions. Specifically, accumulation life after overload was 311,700 cycles and 259,898 cycles, respectively, as can be seen in Table 5. Furthermore, studies on single overloading reveal that the overload ratio is the most effective parameter in controlling crack growth. Studies described in ${ }^{4}$ report an increase of fatigue life of about two- and six-fold as a result of using an overload ratio of 1.5 and 2, respectively. Also, $i^{27}$ the magnitude of the retardation ratio is shown to be inversely proportional to the YS of 2024 aluminum alloy. In the present study the results are similar with first case, the overload ratio of 2 indicated a significant increase in fatigue life for the RRA and T6I4-65 conditions; however, the observed retardation behavior for both conditions were divergent in relation to second case.

Moreover, for the three conditions after applied overload a full crack arrest occurred, as shown in Figure 15. This suggests that the delay phenomenon of fatigue crack growth that took place after a single overload can be explained by compressive residual stress ahead of the crack tip rather than the crack closure mechanisms behind the crack tip. Accordingly, both T6I4-65 and RRA conditions could be key roles in crack growth retardation within the transition period and could be very useful in ensuring structural integrity.

\subsection{Influence of ageing treatment on the crack closure phenomenon with applied overload}

In this section the influence of the three ageing conditions, with a single applied overload, on the crack closure phenomenon is considered. Figure 16 displays the single applied overload effect on the COD, as a function of the cycle fraction, for the T7451, T6I4-65, and RRA conditions. In this particular case, the COD versus cycle fraction curves were measured after an applied overload corresponding to 57,864 cycles, 128,098 cycles and 426,713 cycles, at moment in that crack lengths were 5.7, 5.8, and $5.9 \mathrm{~mm}$, respectively, as shown in Table 4 .

Thus, the superposition effect of single tensile overload on the COD values in relation to COD values before application overload can be compared as follows: for the T7451 condition COD values were of 5.7 and changed to $5.9 \mu \mathrm{m}$, while for the T6I4-65 condition of 4.8 dropped to $4.4 \mu \mathrm{m}$ and for the RRA condition of 3.9 changed to $4.4 \mu \mathrm{m}$. Accordingly, it can be noted from Figure 17, which shows COD versus $\Delta K$ curves at the moment of applied overload, that achieved COD values were: $12 \mu \mathrm{m}$ for the T7451 condition; $12.3 \mu \mathrm{m}$ for the T6I4-65 condition; and $16.9 \mu \mathrm{m}$ for the RRA condition. As a result, overload effect produced higher monotonic

Table 5. Results from the fatigue test with single applied overload for the T7451, T6I4-65, and RRA conditions. The calculation of monotonic plastic zone was performed according to equation: $r_{y}=\frac{1}{6 \pi}\left(\frac{K_{\max }}{\sigma_{\text {yied }}}\right)^{2}[\mu \mathrm{m}]$

\begin{tabular}{lcccccc}
\hline Condition & $\begin{array}{c}\text { Crack length at } \\
\text { overload }(\mathrm{mm})\end{array}$ & $\begin{array}{c}\text { Plastic zone at } \\
\text { overload } \mathrm{r}_{\mathrm{y}}(\mu \mathrm{m})\end{array}$ & $\begin{array}{c}\text { Cycles at } \\
\text { overload } \\
\text { application (Nol) }\end{array}$ & $\begin{array}{c}\text { Delay cycles due } \\
\text { to overload (Nd) }\end{array}$ & Fatigue life (Nf) & $\begin{array}{c}\text { Accumulation } \\
\text { life (Nf - Nol) }\end{array}$ \\
\hline T7451 & 5.7 & 75.2 & 57,581 & 6,148 & 108,888 & 51,307 \\
T6I4-65 & 5.8 & 97.6 & 117,190 & 218,080 & 377,088 & 259,898 \\
RRA & 5.9 & 78.9 & 425,877 & 274,471 & 737,577 & 311,700 \\
\hline
\end{tabular}


plastic zone size $(97.6 \mu \mathrm{m})$ in the T6I4-65 condition than in the other two conditions, as shown in Table 4.

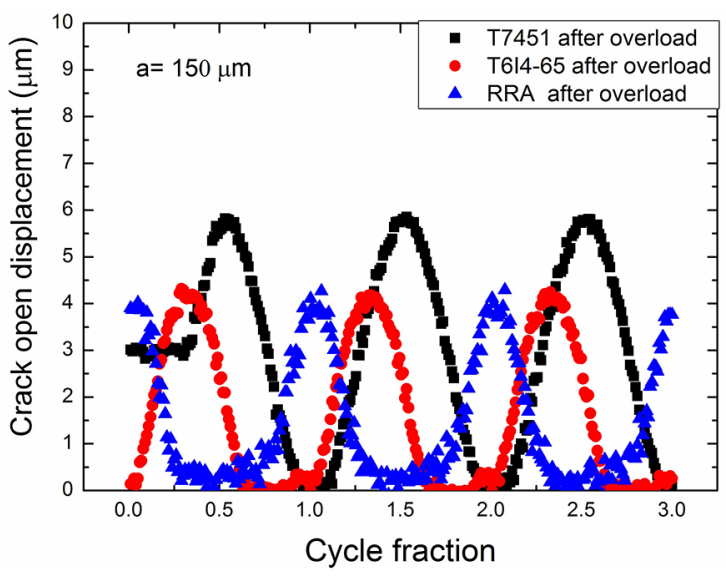

Figure 16. The COD versus cycle fraction curves for the T7451, T6I4-65, and RRA conditions at distance of $\mathrm{a}=150 \mu \mathrm{m}$ behind the crack tip after applied overload of 57,864 cycles, 128,098 cycles, and 426,713 cycles

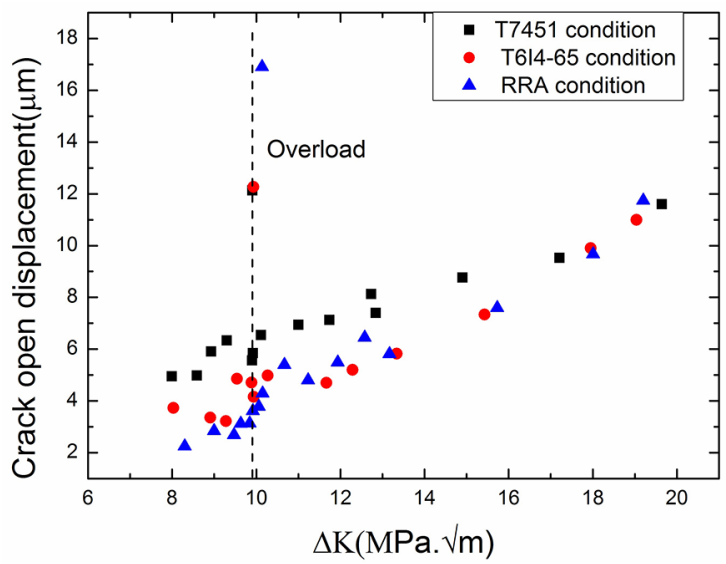

Figure 17. COD versus $\Delta K$ curves with achieved $C O D$ values at the moment of applied overload for the T7451, T6I4-65, and RRA conditions
This represented an increase of $29.7 \%$ and $28.3 \%$ in relation to the T7451 and RRA conditions, respectively. This can be explained by higher ductility and lower YS for the T6I4-65 condition.

Furthermore, results reported $\mathrm{in}^{28}$ revealed that after the application of a single overload take place an increase in COD occurs, followed by acceleration due to the absence of near tip crack closure. Furthermore, a short-lived acceleration of crack growth right after the application of a single tensile overload is only observed for a bigger overloading ratio ${ }^{29}$. These features are considered as the crack tip blunting effects ${ }^{30}$.

This suggests that in the present case the crack tip blunting effects likely took place for both the T7451 and RRA conditions, due to both increase COD values and of the overload ratio of 2 .

Additionally, overload effect also produced significant differences in the striations spacing among the three conditions, as can be noted in Figure 18, which shows SEM fractographs focused at the location of the overload. The purpose of this examination was to consider the arrangement of crack growth striations following propagation beyond the overload region in the alloy treated by the three conditions.

The appearance of striations across the fractured surface was tortuous for the T7451, T6I4-65, and RRA conditions, with spacing in the range of 3.94-9.05 $\mu \mathrm{m}, 30.68-34.65$ $\mu \mathrm{m}$, and 14.82-17.63 $\mu \mathrm{m}$, respectively. In Figure 18 (a-c) it is also possible to observe narrow flat facets for the T7451 condition, while for both T6I4-65 and RRA conditions multiple large flat facet are observed.

The crack growth mechanism depends on the crack driving force, which varies between pure Mode I in the main crack, and a mixture of Mode I and Mode II and at locations of irregular fracture surface within the main crack. Surface roughness analysis was performed for the T7451, T6I465 , and RRA conditions, based on the surface roughness parameter RS according to the ASM Handbook ${ }^{31}$. RS is the ratio $\mathrm{RS}=\mathrm{St} / \mathrm{A}$ given from the true surface area, $\mathrm{St}$, divided
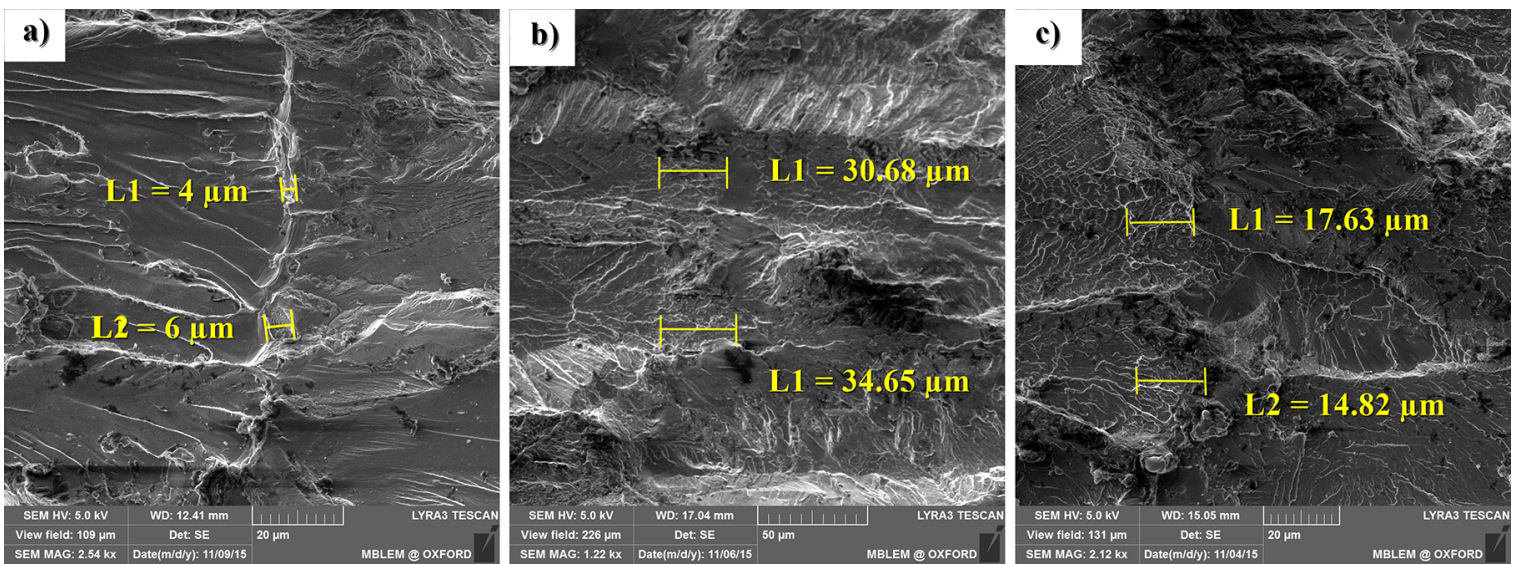

Figure 18. SEM fractographs of the striation region after overload of the alloy in three conditions (a) T7451, (b) T6I4-65, and (c) RRA (crack propagation direction is from left to right) 
by the projected area, A. These parameters were obtained using Alicona optical Infinite Focus 3D micro-coordinate measurement equipment. RS values were measured along chosen sections corresponding to equivalent crack growth positions for the three conditions investigated, as can be seen in Figure 19. The average values measured were 1.23 for T7451, 1.15 for, T6I4-65, and 1.19 for RRA, indicating higher surface roughness for the T7451 condition.

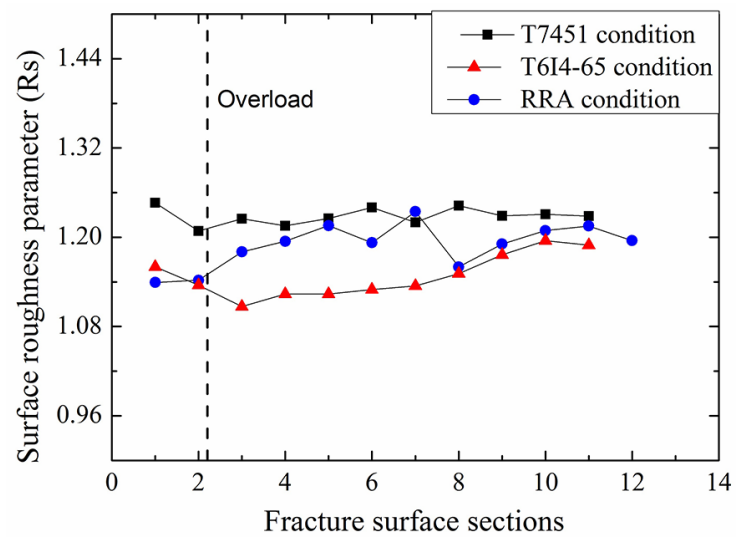

Figure 19. Surface roughness parameter versus fracture surface sections from the three conditions investigated

It is well known that fatigue crack growth in aluminum alloys depend on a combination of some factors: (i) the state of recrystallization, (ii) grain boundary strength, (iii) intensity and type of texture, and (iv) propensity for slip band formation.

Moreover, it was recently reported that interrupted ageing and RRA produce bimodal microstructures containing both shearable and shear-resistant precipitates, and can simultaneously increase both the YS and ductility in the aluminum alloys, as shown in Table $1^{10}$.

Accordingly, the influence of a combination of shearable and non-shearable precipitates contribute to this formation: (a) slip bands as a consequence of the successive dislocations cutting through shearable precipitates, whereby softening occurs as the effective size of the particles decrease, and (b) strong precipitates that are non-shearable when their size exceeds a critical limit, with the inter-particle spacing of non-shearable precipitates controlling the effective length of the slip bands ${ }^{32}$. In the aluminum alloy the slip is classified into two types: wavy and planar. For a wavy slip, the slip bands exhibit a homogeneous structure while for a planar slip situation they have a heterogeneous structure ${ }^{33}$. Thus, this slip band characteristic is known as the slip planarity and it is one of the main driving forces controlling fatigue crack propagation.

In the present study, the RRA condition exhibited large blocky facets in the low-moderate $\Delta \mathrm{K}$ region, while the T6I4-65 condition exhibited small blocky facets; both conditions exhibited shallow pockets, whereas the T7451 condition, due to low ductility and absence of the bimodal microstructure, exhibited only deep pockets, as shown in Figures 7-10. Consequently, these morphological features of the fracture surface contributed to the observed crack closure phenomenon of the three conditions.

Thus, after the crack has overcome the monotonic plastic zone size, which occurs at the incident of the overload, its consequence on the crack closure phenomenon can be explained this way:

- It is shown experimentally that the size of the zone of residual compression is increased after a single tensile overload; the same is associated with monotonic plastic zone size. In the present study, the T6I4-65 condition obtained a higher monotonic plastic zone size, followed by the RRA and T7451 conditions, respectively, as shown in Table 4, indicating plane strain condition when compared with the thickness of the material. However, for all three conditions a full crack arrest took place as a function of compressive residual stresses generated. Thus, only after the fatigue crack progresses through the monotonic plastic zone, and both compressive residual stresses and monotonic plastic zone size can contribute to likely plasticity-induced fatigue crack closure in the wake of the crack. This suggests that a plasticity-induced crack closure phenomenon was predominated for the T6I4-65 condition, as consequence of its higher plastic deformation left in the wake of a fatigue crack, due to the monotonic plastic zone size and compressive residual stress.

- On the other hand, results reported in ${ }^{34}$ show that roughness does not arise from the overload plasticity, but from the slip planarity and crack-path tortuosity. Hence, roughness is expected to play a role in planar slip in the aluminum alloy ${ }^{34}$. In the present case, the RRA condition showed a higher predominance of slip planarity and crack path tortuosity, as shown in Figure 10(c). Furthermore, crack branching was evidenced in the moderate-high $\Delta \mathrm{K}$ region; this feature can also contribute to increase roughness of the RRA condition, as was seen in Figure 19, such that after applied overload occurs an increase of roughness also occurs. Thus, this specific case suggests that two factors are predominant in the RRA condition during the crack closure phenomenon: crack branching and fracture surface roughness.

- Moreover, microstructural features, such as the grain size, also influence the extent of roughnessinduced crack closure. Namely, asperity ridges, if they result from fretting action, can be formed with the same probability anywhere on the fracture surface, and surface roughness could arise from a tortuous crack path due to microstructural effects ${ }^{34}$. This feature was found for the T7451 condition, 
which showed higher surface roughness on the fractured surface, as shown in Figure 19. Results reported $\mathrm{in}^{35}$ exposed the presence of a significant non-plasticity contribution to closure for the 7050T7451 material, but the crack surface roughness, which promotes lower effective crack driving forces due to the activation of roughness, induced crack closure. In this case, the tensile properties found in the present study were similar. Accordingly, this suggests that for the T7451 condition the roughness-induced crack closure was predominant.

\section{Concluding Remarks}

In the present work two types of ageing heat treatment were performed: interrupted ageing and RRA conditions. The main aim was to evaluate their influence on the tensile properties, mainly fatigue crack growth rate, and fracture processes in the low-moderate $\Delta \mathrm{K}$ region. It was recently reported that bimodal microstructures, containing both shearable and shear-resistant precipitates, produce competing mechanisms that influence the tensile properties. Thus, we investigated the contribution of both T6I4-65 and RRA conditions on the crack closure phenomenon, and the consequence the single applied overload effect in the retardation of fatigue crack growth. All these features were compared with the traditional T7451 condition in current use. The main results can be summarized as follows:

1. The RRA condition showed greater tensile property enhancement of YS and UTS $(8.5 \%$ and $3.5 \%$, respectively) in relation to the $\mathrm{T} 7451$ condition, while achieving an increase in ductility of $22.5 \%$, while the T7451 condition obtained $3.7 \%$. Thus, it is possible to substantially increase the ductility of the alloy without detrimental effects on the yield stress.

2. The T6I4-65 condition showed lower YS and UTS (8.5\% and $10.9 \%$, respectively) in relation to the T7451 condition; however, it obtained an $38.7 \%$ increase in ductility.

3. In the low $\Delta \mathrm{K}$ region, the RRA condition displayed better fatigue crack growth rate resistance than the two other conditions.

4. Both T6I4-65 and RRA conditions contributed to the enhancement of crack closure phenomenon in the low-moderate $\Delta \mathrm{K}$ region, and, accordingly, increased fatigue crack growth resistance in relation to the T7451 condition.

5. The applied overload effect was shown to benefit both the T6I4-65 and RRA conditions, increasing accumulation life by 5 - and 6-fold, respectively, when compared with the T7451 condition. This suggests the structural integrity in the aluminum alloy in both cases.
6. Both conditions contributed to the increased occurrence of planar slips, with large flat facet features for the RRA condition, and small flat facets for the T6I4-65 condition, as consequence of competing mechanisms from bimodal microstructures.

\section{Acknowledgements}

This work was supported by the Coordenação de Aperfeiçoamento de Pessoal de Nivel Superior (CAPES) under the Grant BEX 2606/15-1 and BEX 2638/15-0. The authors also acknowledge the contributions of AM Korsunsky, T. Sui and E. Salvati in the MBLEM laboratory at Oxford University.

\section{References}

1. Desmukh MN, Pandey RK, Mukhopadhyay AK. Effect of aging treatments on the kinetics of fatigue crack growth in 7010 aluminum alloy. Materials Science and Engineering: A. 2006;435-436:318-326.

2. Daneshpour S, Koçak M, Langlade S, Horstmann M. Effect of overload on fatigue crack retardation of aerospace Al-alloy laser welds using crack-tip plasticity analysis. International Journal of Fatigue. 2009;31(10):1603-1612.

3. Zhu BH, Xiong BQ, Zhang Y, Zhang JB, Wang F, Li ZH. Microstructure and properties characteristic during interrupted multi-step aging in Al-Cu-Mg-Ag-Zr alloy. Rare Metals. 2011;30(4):419-423.

4. Sarkheil S, Foumani MS. Numerical and experimental study on the optimization of overload parameters for the increase of fatigue life. Aerospace Science and Technology. 2014;35:80-86.

5. Feng D, Zhang XM, Liu SD, Wang T, Wu ZZ, Guo YW. The effect of pre-ageing temperature and retrogression heating rate on the microstructure and properties of AA7055. Materials Science and Engineering: A. 2013;588:34-42.

6. Wang YL, Pan QL, Wei LL, Li B, Wang Y. Effect of retrogression and reaging treatment on the microstructure and fatigue crack growth behavior of 7050 aluminum alloy thick plate. Materials \& Design. 2014; 55:857-863.

7. Risanti DD, Yin M, Rivera Díaz del Castillo PEJ, van der Zwaag S. A systematic study of the effect of interrupted ageing conditions on the strength and toughness development of AA6061. Materials Science and Engineering: A. 2009;523(1-2):99-111.

8. Marlaud T, Deschamps A, Bley F, Lefebvre W, Baroux B. Evolution of precipitate microstructures during the retrogression and re-ageing heat treatment of an $\mathrm{Al}-\mathrm{Zn}-\mathrm{Mg}-\mathrm{Cu}$ alloy. Acta Materialia. 2010;58(14):4814-4826.

9. Burba ME, Caton MJ, Jha SK, Szczepanski CJ. Effect of Aging Treatment on Fatigue Behavior of an Al-Cu-MgAg Alloy. Metallurgical and Materials Transactions A. 2013;44(11):4954-4967. 
10. Chen Y, Weyland M, Hutchinson CR. The effect of interrupted aging on the yield strength and uniform elongation of precipitation-hardened Al alloys. Acta Materialia. 2013;61(15):5877-5894.

11. ASTM International. ASTM E 647 - Standard Method for Measurement of Fatigue Crack Growth Rates. West Conshohocken: ASTM International; 2005.

12. de Matos PFP, Nowell D. Experimental and numerical investigation of thickness effects in plasticity-induced fatigue crack closure. International Journal of Fatigue. 2009;31(11-12):1795-1804.

13. Lumley RN, Polmear IJ, Morton AJ. Development of mechanical properties during secondary aging in aluminium alloys. Materials Science and Technology. 2005;21(9):1025-1032.

14. Gupta VK, Agnew SR. Fatigue crack surface crystallography near crack initiating particle clusters in precipitation hardened legacy and modern $\mathrm{Al}-\mathrm{Zn}-\mathrm{Mg}-\mathrm{Cu}$ alloys. International Journal of Fatigue. 2011;33(9):1159-1174.

15. Schijve J. The application of small overloads for fractography of small fatigue cracks initiated under constant-amplitude loading. International Journal of Fatigue. 2015;70:63-72.

16. Chen YQ, Pan SP, Zhou MZ, Yi DQ, Xu DZ, Xu YF. Effects of inclusions, grain boundaries and grain orientations on the fatigue crack initiation and propagation behavior of 2524-T3 Al alloy. Materials Science and Engineering: A. 2013;580:150-158.

17. Antunes FV, Chegini AG, Branco R, Camas D. A numerical study of plasticity induced crack closure under plane strain conditions. International Journal of Fatigue. 2015;71:7586.

18. Sadananda K, Vasudevan AK, Holtz RL, Lee EU. Analysis of overload effects and related phenomena. International Journal of Fatigue. 1999;21(Suppl 1):S233-S246.

19. Yusof F, Lopez-Crespo P, Withers PJ. Effect of overload on crack closure in thick and thin specimens via digital image correlation. International Journal of Fatigue. 2013;56:17-24.

20. Zhang W, Liu Y. Plastic zone size estimation under cyclic loadings using in situ optical microscopy fatigue testing. Fatigue \& Fracture of Engineering Materials \& Structures. 2011;34(9):717-727.

21. Mathieu F, Hild F, Roux S. Identification of a crack propagation law by digital image correlation. International Journal of Fatigue. 2012;36(1):146-154.

22. Bichler C, Pippan R. Effect of single overloads in ductile metals: A reconsideration. Engineering Fracture Mechanics. 2007;74(8):1344-1359.
23. Lee SY, Liaw PK, Choo H, Rogge RB. A study on fatigue crack growth behavior subjected to a single tensile overload: Part I. An overload-induced transient crack growth micromechanism. Acta Materialia. 2011;59(2):485-494.

24. Xiao L, Ye D, Chen C, Liu JZ, Zhang L. Instrumented indentation measurements of residual stresses around a crack tip under single tensile overloads. International Journal of Mechanical Sciences. 2014;78:44-51.

25. Järvenpää A, Karjalainen LP, Jaskari M. Effect of grain size on fatigue behavior of Type $301 \mathrm{LN}$ stainless steel. International Journal of Fatigue. 2014;65:93-98.

26. Vasco-Olmo JM, Díaz FA, García-Collado A, Dorado-Vicente R. Experimental evaluation of crack shielding during fatigue crack growth using digital image correlation. Fatigue \& Fracture of Engineering Materials \& Structures. 2015;38(2):223-237.

27. Kermanidis AT, Pantelakis SG. Prediction of crack growth following a single overload in aluminum alloy with sheet and plate microstructure. Engineering Fracture Mechanics. 2011;78(11):2325-2337.

28. Ling MR, Schijve J. The effect of intermediate heat treatments on overload induced retardations during fatigue crack growth in an al-alloy. Fatigue \& Fracture of Engineering Materials \& Structures. 1992;15(5):421-430.

29. Wang C, Wang XG, Ding ZY, Xu YG, Gao ZG. Experimental investigation and numerical prediction of fatigue crack growth of 2024-T4 aluminum alloy. International Journal of Fatigue. 2015;78:11-21.

30. de Matos PFP. Plasticity induced fatigue crack closure: Modelling and Experiments. [Thesis]. Oxford: University of Oxford, Department of Engineering Science; 2007.

31. Underwood EE, Banerji K. Quantitative Fractography. In: $A S M$ Handbook Volume 12: Fractography. Materials Park: ASM International; 1998.

32. Blankenship CP Jr, Hornbogen E, Starke EA Jr. Predicting slip behavior in alloys containing shearable and strong particles. Materials Science and Engineering: A. 1993;169(1-2):33-41.

33. De PS, Mishra RS, Baumann JA. Characterization of high cycle fatigue behavior of a new generation aluminum lithium alloy. Acta Materialia. 2011;59(15):5946-5960.

34. Vasudeven AK, Sadananda K, Louat N. A review of crack closure, fatigue crack threshold and related phenomena. Materials Science and Engineering: A. 1994;188(1-2):1-22.

35. Walker KF, Wang CH, Newman JC Jr. Closure measurement and analysis for small cracks from natural discontinuities in an aluminium alloy. International Journal of Fatigue. 2016;82(Pt 2):256-262. 